Check for updates

Cite this: RSC Adv., 2019, 9, 20100

Received 3rd June 2019

Accepted 20th June 2019

DOI: 10.1039/c9ra04176a

rsc.li/rsc-advances

\section{Identification of the early intermediates formed in ozonolysis of cis-2-butene and limonene: a theoretical and matrix isolation study $\uparrow$}

\begin{abstract}
Shan-shan Li, ${ }^{a}$ Xiao-yang Yang, ${ }^{b}$ Yi-sheng $\mathrm{Xu}^{\mathrm{b}}$ and Lei Jiang (DD *a
This study combined quantum chemical calculations and the matrix isolation technique to identify the formation of primary intermediates from the ozonolysis of cis-2-butene and limonene. Quantum chemical calculations were conducted under the framework of density functional theory (DFT) at M06$2 x / 6-311+(d, p)$ level of theory to predict the possible mechanism as well as the new absorption bands. New bands whose intensity increased with annealing, were observed in twin jet deposition, which indicated the formation of primary ozonides, $\mathrm{Cl}$ and secondary ozonides in the investigated systems. Isotopic labeling $\left({ }^{18} \mathrm{O}\right)$ experiments further supported the assignment of observed bands. The results and findings in this study would enrich the understanding of the reaction mechanism of alkene ozonolysis.
\end{abstract}

\section{Introduction}

Ozone readily reacts with alkenes through association with $\mathrm{C}=\mathrm{C}$ double bonds. Aldehydes and/or ketones, organic acids as well as other fragmentation products are ultimately produced following the cleavage of the $\mathrm{C}=\mathrm{C}$ double bond in alkenes. The widely accepted ozonolysis mechanism was originally proposed by Criegee. ${ }^{1}$ The initial step involves a highly exothermic concerted 1,3-dipolar cyclo-addition of ozone to the $\mathrm{C}=\mathrm{C}$ double bond forming primary ozonide (POZ) with the 1,2,3trioxolane ring. Second, the POZ with excess energy would undergo rapid decomposition of the trioxolane ring to produce a primary carbonyl and a highly reactive carbonyl oxide intermediate referred to as the Criegee intermediate (CI). The CI can react unimolecularly, be stabilized by collisions with the surrounding molecules or recombine with the produced carbonyl to produce the more stable secondary ozonide (SOZ) with the 1,2,4-trioxolane ring., ${ }^{2,3}$ Since the contribution of secondary organic aerosol (SOA) formation from vastly emitted biogenical compounds to aerosol loading was proposed in $1960,{ }^{4}$ the ozonolysis of monoterpenes has drawn great attention because these reactions may promote the formation of urban SOAs. ${ }^{5}$ When emitted to the atmosphere, monoterpenes may participate in SOA formation ${ }^{6,7}$ due partly to their reactions with $\mathrm{O}_{3}$ leading to water-soluble products, which can act as

${ }^{a}$ Beijing Municipal Research Institute of Environmental Protection, Beijing 100037, China. E-mail: 154249704@qq.com; jiangle3657@sina.com; Fax: +86-10-68314675

${ }^{b}$ State Key Laboratory of Environmental Criteria and Risk Assessment, Chinese Research Academy of Environmental Sciences, Beijing 100012, China. E-mail: xuys@ craes.org.cn; yangxy@craes.org.cn

† Electronic supplementary information (ESI) available. See DOI: 10.1039/c9ra04176a
$\mathrm{CCN}^{8}{ }^{8}$ Limonene is recognized as the second major terpene emitted by natural source in the atmosphere, ${ }^{9-12}$ and the oxygenated products of limonene ozonolysis could contribute to SOA formation as those of pinene ozonolysis do. ${ }^{\mathbf{8 , 1 1}}$

Experimental and theoretical researchers have focused on product determination and thermodynamic/kinetic parameter evaluation of limonene ozonolysis. ${ }^{9-16}$ The rate constant of limonene ozonolysis was measured to be $2.1 \pm 0.15 \times 10^{-18} \mathrm{~cm}^{3}$ per molecule per second based on relative rate techniques by Khamaganov et al. ${ }^{\mathbf{1 0}}$ which well corresponded with the previous experimental results obtained by Shu et al. ${ }^{13}$ The major products including limonic acid, keto-limonene, limononaldehyde, and limononic acid were identified by several groups. ${ }^{\mathbf{1 0 , 1 1 , 1 4}}$ Recently Jiang et al. ${ }^{15}$ and Ayadi et al. ${ }^{16}$ attempted to reveal the mechanism of limonene ozonolysis using theoretical methods, and the major reaction pathway with branching ratio was proposed. Despite these efforts, the formed CIs from limonene ozonolysis are not verified in detail, which impedes the unambiguous explanation of the mechanism for limonene ozonolysis. This can be partly attributed to the shortcomings of current experimental instruments on detecting the short-lived substances. Currently, matrix isolation ${ }^{\mathbf{1 7}, 18}$ has been becoming one of the most popular techniques to investigate short-lived substances $^{19-25}$ including CIs. ${ }^{20,21,24}$ In the matrix isolation system, the concerned reaction systems are trapped in argon matrix at temperatures lower to $\sim 14 \mathrm{~K}$, allowing for very short mixing time. Thus, the short-lived substances can be isolated and stabilized by the matrix molecules around. The infrared spectroscopy conducted under matrix isolation can provide reliable characterization of CIs and has been applied extensively in the exploration addressing alkene ozonolysis. Hoops et al. observed the CIs formed in the ozonolysis of cyclopentadiene and cyclopentene by matrix isolation. ${ }^{21}$ Clay et al. studied the 
mechanism of the ozonolysis of cis-2-butene by matrix isolation and successfully detected CIs. ${ }^{22}$ However, the standard infrared spectra of CIs are rarely reported, which exacerbated the difficulty of CI recognition and mechanism validation. Meanwhile, quantum chemical calculation has been widely used to explore the reaction mechanisms and analyze the reaction products, which provides additional evidence to overcome the shortcomings of matrix isolation infrared spectroscopy. ${ }^{25}$

In this study, we combined quantum chemical calculation and matrix isolation infrared spectroscopy to confirm CI formation and reveal the mechanism of the ozonolysis of cis-2butene and limonene. The possible reaction pathways, the corresponding rate constants, and spectroscopic information were predicted by quantum chemical calculations, which were further verified by matrix isolation infrared spectroscopy. ${ }^{18} \mathrm{O}$ isotope labeling was utilized to additionally characterize the early intermediates. cis-2-Butene was selected to validate the reliability of our experimental and theoretical methods, and provided fundamental understanding to the study on limonene ozonolysis.

\section{Materials and methods}

\subsection{Chemicals}

Limonene (99.0\%, TCI Shanghai, China), cis-2-butene (99.0\%, Deyang, China), 1-methyl-1-cyclohexene (98.0\%, TCI Shanghai, China) and 1-methyl-1,4-cyclohexadiene (97.0\%, Alfa Aesar, China) were used without any further purification. $\mathrm{O}_{3}$ and ${ }^{18} \mathrm{O}_{3}$ were produced by Tesla coil discharge of $\mathrm{O}_{2}$ (99.999\%, Deyang, China) and ${ }^{18} \mathrm{O}_{2}$ (99.5\%, Shanghai Research Institute of Chemical Industry, China), respectively, and then trapped at 77 $\mathrm{K}$ to wipe off residual $\mathrm{O}_{2}$ and trace gases. Argon (99.999\%, Deyang, China) was selected as the matrix gas to dilute the samples in all the experiments. The argon/sample ratios were all adjusted to be $200 / 1$.

\subsection{Blank experiments}

Prior to each co-deposition experiment, blank experiments including deposition and annealing were conducted on all of the parent compounds. The obtained blanks were used as authentic spectra of the pure parent compounds, which provided unambiguous identification of product bands and the baseline for the extent of the reactions.

\subsection{Ozonolysis experiments}

All the experiments were conducted on a matrix isolation apparatus. The low temperature $(\sim 14 \mathrm{~K})$ was obtained by a closed-cycle helium compressor-cooled cryostat (PT-SHI-4-5, Janis Research Company, USA) in a vacuum chamber. The pressure inside the cryostat chamber was monitored by a pressure gauge (WRG-NW25, Edward, UK). A base pressure of (2-5) $\times 10^{-5}$ mbar was recorded at the initial stage of each experiment. The deposition process was performed as twin jet mode, that is, the $\mathrm{Ar} / \mathrm{O}_{3}$ and $\mathrm{Ar} /$ sample mixtures were inputted into the cold window through two separate nozzles in the cold head, which lasted for $\sim 210 \mathrm{~min}$ at $\sim 5 \mathrm{mmol} \mathrm{h}^{-1}$. ZnSe windows were equipped to the vacuum vessel, which was located at the sample beam of the FTIR spectrometer (Vertex 80v, Bruker) for the duration of the experiment. The spectra were recorded from 400 to $4000 \mathrm{~cm}^{-1}$ averaging 32 scans at a resolution of $0.5 \mathrm{~cm}^{-1}$. After the $14 \mathrm{~K}$ spectrum was recorded, the temperature in the chamber was raised to $35 \mathrm{~K}$, which was maintained for $30 \mathrm{~min}$ to permit diffusion and/or reaction, and the $35 \mathrm{~K}$ spectrum was recorded after the chamber was cooled down again to $14 \mathrm{~K}$. The data were analyzed by OPUS 7.2 software. The experiments were triplicated to ensure the reproducibility.

\subsection{Computational methods}

All theoretical calculations in this paper were performed by Gaussian 09. ${ }^{26}$ Geometry optimizations and vibrational calculations were carried out under the framework of density functional theory (DFT) at M06-2x/6-311+(d, p) level of theory. ${ }^{27}$ The optimized structures were determined to be minima with no imaginary frequency or to be transition states with one imaginary frequency by vibrational calculations, and all vibrational frequencies are scaled by $0.944 .^{28}$ The potential energy surface was constructed at $\operatorname{CCSD}(\mathrm{T}) / 6-311+(\mathrm{d}, \mathrm{p}) / / \mathrm{M} 06-2 \mathrm{x} / 6-311+(\mathrm{d}, \mathrm{p})$ level of theory. The KiSThelP software ${ }^{29}$ was employed to calculate the rate constants of the concerned elementary steps based on TST theory.

\section{Results and discussion}

\subsection{Ozonolysis of cis-2-butene}

3.1.1 Theoretical predicted mechanism. Fig. 1 and $\mathrm{S} 1 \dagger$ interpret the mechanism of cis-2-butene ozonolysis and the corresponding potential energy surface (PES), respectively. A van der Waals complex (Vdw) with the binding energy of $-2.11 \mathrm{kcal} \mathrm{mol}^{-1}$ forms when cis-2-butene interacts with ozone. Then, primary ozonide (POZ) can be produced from Vdw via a transition state. The formation of POZ is exothermic by $53.67 \mathrm{kcal} \mathrm{mol}^{-1}$ with a low potential barrier of $2.37 \mathrm{kcal} \mathrm{mol}^{-1}$. The $\mathrm{C}-\mathrm{C}$ bond and $\mathrm{O}-\mathrm{O}$ bond in $\mathrm{POZ}$ can elongate and finally break, leading to aldehyde and Criegee intermediate (CI). POZ formation, $\mathrm{POZ}$ decomposition and $\mathrm{SOZ}$ formation is exothermic with low or moderate potential barriers. The production of $\mathrm{CI}$ is exothermic by $23.60 \mathrm{kcal} \mathrm{mol}^{-1}$ with a moderate potential barrier of $13.58 \mathrm{kcal} \mathrm{mol}^{-1}$. The formation of SOZ is exothermic by $44.58 \mathrm{kcal} \mathrm{mol}^{-1}$, implying that SOZ is relatively stable and, therefore, could be detected more easily than CI. The optimized molecular structures of the involved substances in Fig. 1 are shown in Fig. S2. $\dagger$

3.1.2 Spectra. Twin jet mode allowing for short reaction time was employed in this study. In the twin jet experiment, a sample of $\mathrm{Ar} /$ cis-2-butene $=200$ was co-deposited with a sample of Ar/ozone $=200$. As illustrated in Fig. 2, some new bands were recorded in the initial $14 \mathrm{~K}$ spectrum of the deposited matrix during the short condensation time, indicating that a rapid reaction occurred when co-depositing cis-2butene and ozone into Ar matrices. Subsequently, this sample was annealed to $35 \mathrm{~K}$ and recooled to $14 \mathrm{~K}$ and an annealed spectrum recorded. New bands at 720, 890, 920, 1062, 1115, $1144,1341,1470$ and $1720 \mathrm{~cm}^{-1}$ were observed. The intensities 


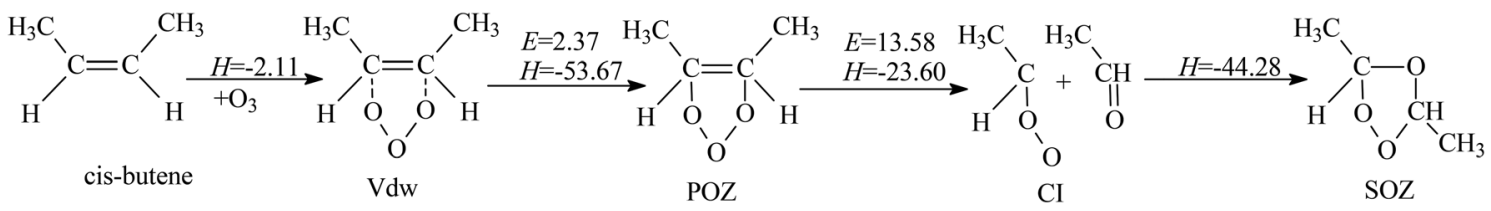

Fig. 1 The mechanism of cis-2-butene ozonolysis embedded with the energy barrier $\Delta E$ and reaction energy $\Delta H$ (all in kcal mol ${ }^{-1}, 298.15 \mathrm{~K}^{2}$. Geometries of the stationary points involved in the stabCl-OO $+\mathrm{H}_{2} \mathrm{O}$ reaction obtained at the M06-2x/6-311+ $\mathrm{G}(\mathrm{d}$, $\mathrm{p})$ level of theory. Bond lengths and intermolecular distances are given in $\AA$.

of the bands appeared at 930, 1039, 1105, 1158, 1231, 1341, 1578 and $1639 \mathrm{~cm}^{-1}$ decreased as annealing, indicating that these bands were produced by the complexed reactants. Similar twin jet experiment was run with the samples of $\mathrm{Ar} /$ cis-2-butene $=$ 200 and $\mathrm{Ar} /{ }^{18} \mathrm{O}_{3}=200 .{ }^{18} \mathrm{O}$ counterparts of the product bands were observed at 692, 875, 904, 1059, 1102, 1138, 1340, 1470, and $1690 \mathrm{~cm}^{-1}$, which were shown in Fig. S3.† Upon annealing, these bands grew substantially, just opposed to their $16 \mathrm{O}$ counterparts. However, interpretation of this phenomenon could not be accurately provided at this time. The new product bands and their assignments are summarized in Table 1.

DFT calculations predict that the two major vibrational modes for POZ are at 703 and $1048 \mathrm{~cm}^{-1}$, which are generally consistent with the two observed experimental bands at 720 and $1062 \mathrm{~cm}^{-1}$. The band at $720 \mathrm{~cm}^{-1}$ shifted for $28 \mathrm{~cm}^{-1}$ when ${ }^{18} \mathrm{O}_{3}$ was employed, which agreed with the predicted ${ }^{18} \mathrm{O}$ shift of $32 \mathrm{~cm}^{-1}$. The symmetric stretching mode of $\mathrm{C}-\mathrm{O}$ ring in $\mathrm{POZ}$ was calculated to be at $1048 \mathrm{~cm}^{-1}$, near the band at $1062 \mathrm{~cm}^{-1}$. This band was theoretically predicted to have an $8 \mathrm{~cm}^{-1}{ }^{18} \mathrm{O}$ shift, in comparison with the $3 \mathrm{~cm}^{-1}$ shift that was experimentally recorded. Given that the ${ }^{18} \mathrm{O}_{3}$ used in our experiments inevitably mixed with minor part of ${ }^{16} \mathrm{O}_{3}$, the isotopic shift observed should be in the range of 0 and the theoretical predicted values, and the product bands observed in ${ }^{18} \mathrm{O}_{3}$ experiments were thus broader (sometimes with no well-resolved band position).
For CI, only one vibrational mode for the antisymmetric stretch of the $\mathrm{C}-\mathrm{O}-\mathrm{O}$ linkage has significant intensity (i.e., $I>40$ $\mathrm{km} \mathrm{mol}^{-1}$ ), which is predicted by DFT calculations. This mode has a predicted ${ }^{18} \mathrm{O}$ shift of $-22 \mathrm{~cm}^{-1}$. The $920 \mathrm{~cm}^{-1}$ band recorded in the experiment is in reasonable agreement with the calculated results, and shows an ${ }^{18} \mathrm{O}$ shift of $-18 \mathrm{~cm}^{-1}$. Some previous matrix isolation studies also reported that the characteristic absorption band of different CIs were at 920$980 \mathrm{~cm}^{-1} \cdot{ }^{21,22,30,31}$ The band at $1720 \mathrm{~cm}^{-1}$ grew with the increase of the $920 \mathrm{~cm}^{-1}$ band upon annealing. The concurrent growth of the band at $1720 \mathrm{~cm}^{-1}$ suggests the formation of acetaldehyde, since CI and acetaldehyde were produced simultaneously and should be trapped in the same matrix cage. Moreover, the experimental ${ }^{18} \mathrm{O}$ shift of the $1720 \mathrm{~cm}^{-1}$ band is $39 \mathrm{~cm}^{-1}$, closely matching the theoretically anticipated shift for acetaldehyde. The bands at $890,1115,1144,1340$, and $1470 \mathrm{~cm}^{-1}$ in this study are assigned to the secondary ozonide (SOZ) of cis-2-butene. The 890 and $1144 \mathrm{~cm}^{-1}$ bands exhibit obvious isotopic shift. No ${ }^{18} \mathrm{O}$ shift was recorded for the bands at 1340 and $1471 \mathrm{~cm}^{-1}$, which were assigned to $\mathrm{CH}_{2}$ bending modes. As shown in Table 1, vibrational modes of the SOZ predicted by theoretical calculations are in reasonable agreement with the experimental bands, and the calculated isotopic shift of each vibrational mode for the ${ }^{18} \mathrm{O}$ isotopomer is close to the observed shift. This well matches the research by Clay et $a .^{22}$ and validates our experimental procedures.
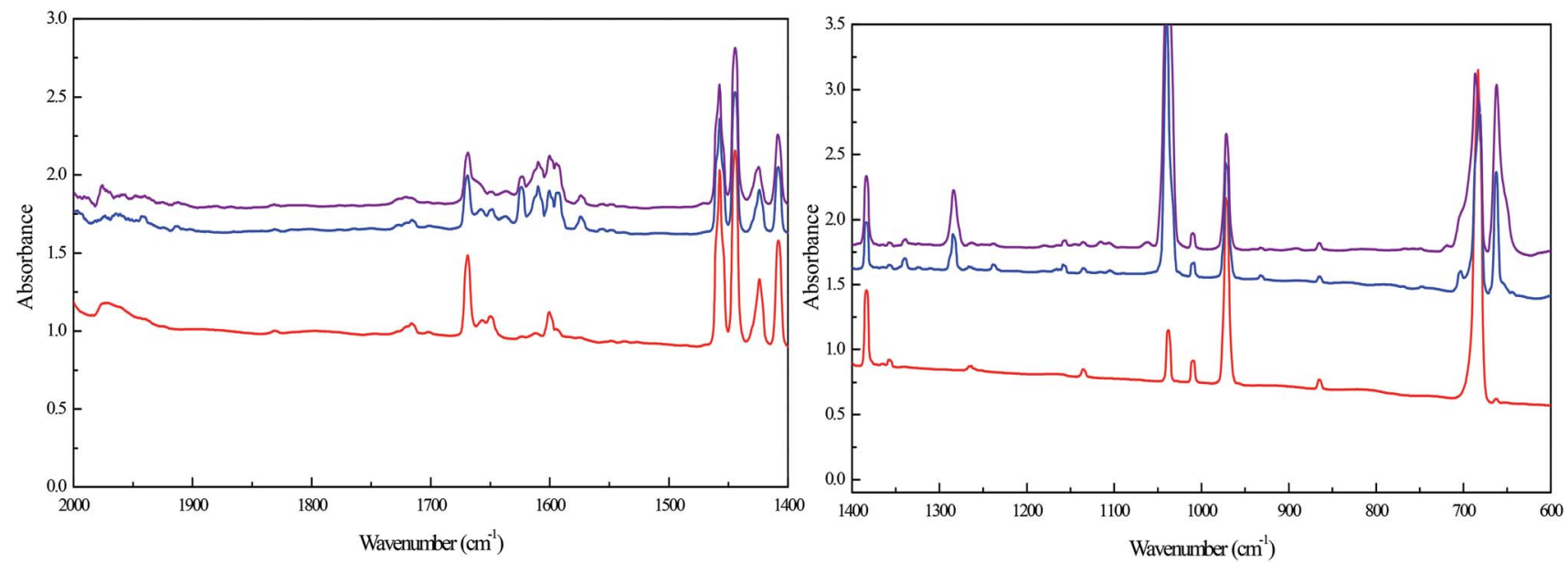

Fig. 2 Infrared spectra of the co-deposition of the samples of Ar/cis-2-butene $=200$ and $\mathrm{Ar} / \mathrm{O}_{3}=200$. The blue line (middle) indicates initial deposition at $14 \mathrm{~K}$ and the purple line (top) represents the spectrum after annealing to $35 \mathrm{~K}$, compared to a blank spectrum of Ar/cis-2-butene $=$ 200 (red, bottom). 
Table 1 Product band positions and assignments in the ozonolysis of cis-2-butene (in $\mathrm{cm}^{-1}$ )

\begin{tabular}{|c|c|c|c|c|}
\hline \multicolumn{2}{|c|}{$\begin{array}{l}\text { Experimental } \\
\text { position and shifts }\end{array}$} & \multicolumn{2}{|c|}{$\begin{array}{l}\text { Calculated position } \\
\text { and shifts }\end{array}$} & \multirow[b]{2}{*}{ Assignment } \\
\hline${ }^{16} \mathrm{O}$ & $\Delta^{18} \mathrm{O}$ & ${ }^{16} \mathrm{O}$ & $\Delta^{18} \mathrm{O}$ & \\
\hline 720 & -28 & 703 & -32 & $\mathrm{POZ}$ \\
\hline 890 & -18 & & & $\mathrm{SOZ}$ \\
\hline 920 & -18 & 912 & -22 & CI \\
\hline 1062 & -3 & 1048 & -8 & $\mathrm{POZ}$ \\
\hline 1115 & -13 & & & SOZ \\
\hline 1144 & - & & & $\mathrm{SOZ}$ \\
\hline 1340 & 0 & & & $\mathrm{SOZ}$ \\
\hline 1470 & 0 & & & $\mathrm{SOZ}$ \\
\hline 1720 & -39 & 1761 & -37 & Acetaldehyde \\
\hline
\end{tabular}

\subsection{Ozonolysis of limonene}

3.2.1 Theoretical predicted mechanism. The mechanism of limonene ozonolysis and corresponding PES are shown in Fig. 3 and $\mathrm{S} 4, \uparrow$ respectively. Ozone can interact with the $\mathrm{C}=\mathrm{C}$ double bond within the carbon ring of the limonene molecule to produce $\mathrm{Vdw} 1$, or interact with the $\mathrm{C}=\mathrm{C}$ double bond within the side chain, leading to Vdw2. The formation of Vdw1 is more favorable than that of Vdw2. The formation of both POZs from the corresponding van der Waals complexes is highly exothermic of $\sim 50 \mathrm{kcal} \mathrm{mol}^{-1}$ with low potential barriers. However, the rate constant calculations suggest that the
Table 2 The calculated rate constants $(298.15 \mathrm{~K})$ of the elementary reactions involved in limonene ozonolysis

\begin{tabular}{lc}
\hline Elementary reactions & Rate constant $^{a}$ \\
\hline Limonene + ozone $\rightarrow$ & $1.90 \times 10^{-15}$ \\
POZ1 & \\
POZ1 $\rightarrow$ CI1 & $1.16 \times 10^{-8}$ \\
POZ1 $\rightarrow$ CI2 & $1.22 \times 10^{-2}$ \\
Limonene + ozone $\rightarrow$ & $1.79 \times 10^{-16}$ \\
POZ2 & \\
POZ2 $\rightarrow$ CI3 & $1.44 \times 10^{-4}$ \\
POZ2 $\rightarrow$ CI4 & $1.49 \times 10^{-7}$
\end{tabular}

${ }^{a}$ The rate constants of unimolecular reaction are in $\mathrm{s}^{-1}$, while the rate constant of bimolecular reaction are in $\mathrm{cm}^{3}$ per molecule per second.

formation of POZ1 is much faster than that of POZ2 by a factor of $\sim 9$, as shown in Table 2 . The reactions associated with POZ1 are therefore considered to be more important in comparison of the reactions related to POZ2. Because POZ1 is asymmetric, the -OOO- ring in POZ1 can be opened by two pathways to produce CI1 and CI2. The potential barrier of CI1 formation is $17.72 \mathrm{kcal} \mathrm{mol}^{-1}$, which is $7.63 \mathrm{kcal} \mathrm{mol}^{-1}$ higher than that of CI2 formation. Moreover, the rate constant of CI2 formation is $\sim 6$ orders of magnitude larger than that of CI1 formation. Therefore CI2 formation is predominant over CI1 formation, and the subsequent reactions of CI1 are not further discussed. Analogously, POZ2 can produce CI3 and CI4 through the rupture of -OOO- ring. The formation of CI3 is anticipated to be

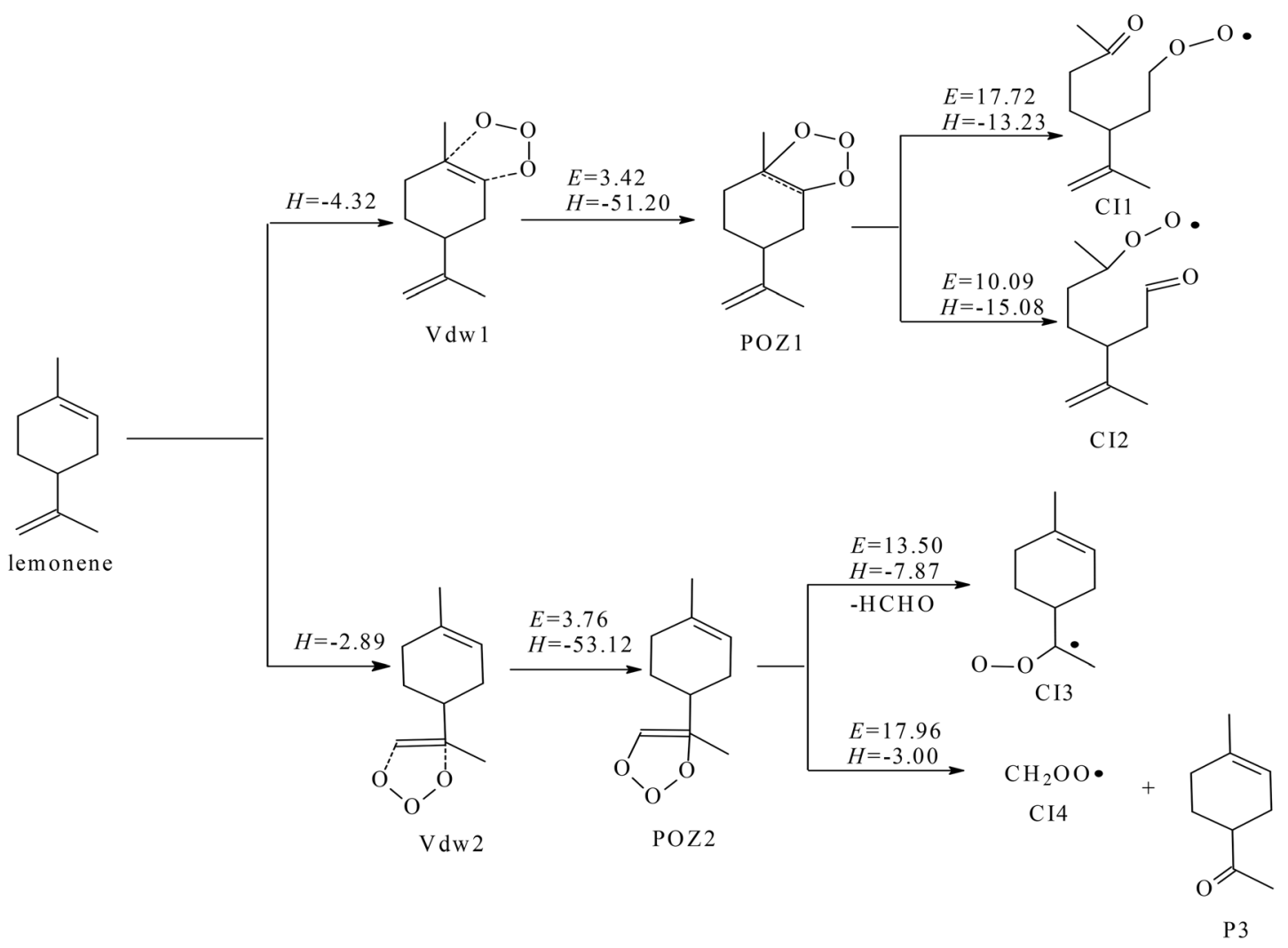

Fig. 3 The mechanism limonene ozonolysis embedded with the potential energy $\Delta E$ and reaction energy $\Delta H$ (all in $\mathrm{kcal} \mathrm{mol}^{-1}, 298.15 \mathrm{~K}_{\text {). }}$ 
much favorable than that of CI4 by judging the corresponding potential barrier and rate constant. The optimized molecular structures of the involved substances in Fig. 3 are shown in Fig. S5 and S6. $\dagger$

3.2.2 Spectra. The sample of Ar/limonene $=200$ was codeposited with a sample of Ar/ozone $=200$ in the twin jet experiment. Fig. 4 illustrates that new absorption bands were more obvious when this sample was subsequently annealed to $35 \mathrm{~K}$. New bands at 656, 930, 945, 1050, 1070, 1151, 1232, 1720, 1758, $\sim 1850$ and $2147 \mathrm{~cm}^{-1}$ were observed. The bands at $\sim 1050, \sim 1070, \sim 1232$ and $\sim 1850$ were broad with no wellresolved peak, which suffered from the interference with limonene and ozone as well. Similar twin jet deposition experiment was run with the samples of $\mathrm{Ar} /$ limonene $=200$ and $\mathrm{Ar} /{ }^{18} \mathrm{O}_{3}=$ 200. The spectra obtained using ${ }^{18} \mathrm{O}$ isotope was only provided in the $\mathrm{ESI}_{\dagger} \dagger$ as reference. The new product bands and their assignments are summarized in Table 3.

$\mathrm{POZ}, \mathrm{CI}$ and $\mathrm{SOZ}$ are potential and reasonable intermediates produced by limonene ozonolysis. Nevertheless, the identification of these intermediates through clear assignments of the absorption bands is nontrivial. The assignments could be achieved by comparing the vibrations and their corresponding isotopic shifts obtained from experimental and theoretical results (Table 3 ). Given that some bands overlapped with reactant bands or other product bands, quantitative conclusion could not be reached for these product bands. Nonetheless, the bands at 656, 930, 945, 1050, 1070, 1151, 1232 and $1720 \mathrm{~cm}^{-1}$ could be reasonably assigned to POZ, CI and SOZ in the light of position and isotopic shifts. Generally, the bands assigned to POZ, CI and SOZ are in reasonable agreement with the theoretical calculations.

CI2/CI3 is calculated to have only one vibrational mode with significant intensity belonging to the antisymmetric stretch of the $\mathrm{C}-\mathrm{O}-\mathrm{O}$ linkage. The calculated vibrational frequencies of the $\mathrm{C}-\mathrm{O}-\mathrm{O}$ stretching mode of $\mathrm{CI} 2$ and $\mathrm{CI} 3$ are 930 and
Table 3 Product band positions and assignments in the ozonolysis of limonene (in $\mathrm{cm}^{-1}$ )

\begin{tabular}{|c|c|c|c|c|}
\hline \multicolumn{2}{|c|}{$\begin{array}{l}\text { Experimental } \\
\text { position and shifts }\end{array}$} & \multicolumn{2}{|c|}{$\begin{array}{l}\text { Calculated } \\
\text { position and shifts }\end{array}$} & \multirow[b]{2}{*}{ Assignment } \\
\hline${ }^{16} \mathrm{O}$ & $\Delta^{18} \mathrm{O}$ & ${ }^{16} \mathrm{O}$ & $\Delta^{18} \mathrm{O}$ & \\
\hline \multirow[t]{2}{*}{656} & -15 & 651 & -12 & SOZ1 \\
\hline & & 885 & & POZ2 \\
\hline 930 & -17 & 925 & -20 & $\mathrm{CI} 2$ \\
\hline \multirow[t]{3}{*}{945} & -11 & 944 & -15 & CI3 \\
\hline & & 968 & & SOZ2 \\
\hline & & 970 & & SOZ1 \\
\hline \multirow[t]{2}{*}{$\sim 1050$} & -3 & 1051 & -8 & SOZ2 \\
\hline & & 1054 & -9 & SOZ1 \\
\hline \multirow[t]{6}{*}{$\sim 1070$} & -6 & 1072 & -8 & POZ2 \\
\hline & & 1075 & -10 & SOZ2 \\
\hline & & 1078 & -8 & POZ1 \\
\hline & & 1087 & & SOZ1 \\
\hline & & 1102 & & POZ1 \\
\hline & & 1125 & & SOZ2 \\
\hline \multirow[t]{4}{*}{1151} & -15 & 1149 & -12 & POZ2 \\
\hline & & 1167 & & SOZ2 \\
\hline & & 1186 & & POZ1 \\
\hline & & 1195 & & SOZ1 \\
\hline \multirow[t]{2}{*}{$\sim 1232$} & -19 & 1226 & -22 & SOZ1 \\
\hline & & 1273 & & SOZ1 \\
\hline 1720 & -28 & 1732 & -31 & Formaldehyde \\
\hline
\end{tabular}

$944 \mathrm{~cm}^{-1}$, respectively. The $926 \mathrm{~cm}^{-1}$ and $945 \mathrm{~cm}^{-1}$ bands observed in the experiment matches well with the calculated results. The intensity of the $945 \mathrm{~cm}^{-1}$ band is much stronger than that of $926 \mathrm{~cm}^{-1}$, suggesting that CI2 is the major CI in limonene ozonolysis. This agrees with our theoretical prediction. Some previous matrix isolation study also reported that the characteristic absorption band of different CIs were at 920$980 \mathrm{~cm}^{-1},{ }^{21,22,30,31}$ which was in good agreement with the observations here.
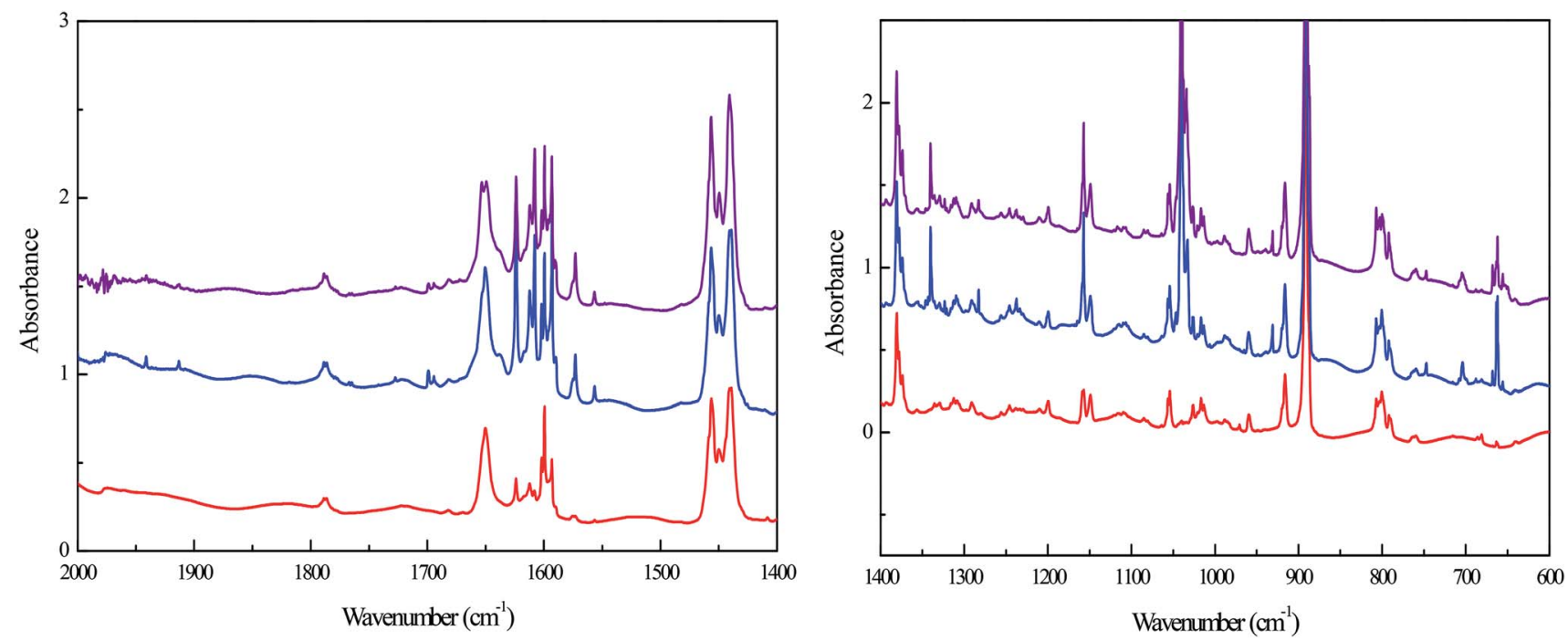

Fig. 4 Infrared spectra of the co-deposition of the samples of $\mathrm{Ar} /$ limonene $=200$ and $\mathrm{Ar} / \mathrm{O}_{3}=200$. The blue line (middle) indicates initial deposition at $14 \mathrm{~K}$ and the purple line (top) represents the spectrum after annealing to $35 \mathrm{~K}$, compared to a blank spectrum of Ar/limonene $=200$ (red, bottom). 


\section{Conclusions}

In this study, the early intermediate products formed during ozonolysis of cis-2-butene and limonene were proposed by quantum chemical calculations, which was verified by matrix isolation infrared spectroscopy. Primary ozonides, Criegee intermediates, and secondary ozonides were identified by comparing the vibrations and their corresponding isotopic shifts obtained from experimental and theoretical results. The ozonolysis of limonene follows the Criegee mechanism, and the dominant pathways in these reactions was revealed. The results and findings in this study would provide theoretical and experimental support for the mechanism of ozonolysis of alkenes.

\section{Conflicts of interest}

All the authors declare no conflict of interest.

\section{Acknowledgements}

This work was financially supported by the National Science Foundation for Young Scientists of China (Grant No. 41405120) and National Natural Science Foundation of China (Grant No. 21607093 and No. 41375133).

\section{References}

1 R. Criegee and G. Wenner, Die Ozonisierung des 9,10Oktalins, Justus Liebigs Ann. Chem., 1949, 564, 9-15.

2 P. S. Bailey, Ozonation in Organic Chemistry: Vol. I Olefinic Compounds; Organic Chemistry, A Series of Monographs, Academic Press, New York, 1978, vol. 39-I.

3 J. G. Calvert, R. Atkinson, J. A. Kerr, S. Madronich, G. K. Moortgat, T. J. Wallington and G. Yarwood, The Mechanisms of the Atmospheric Oxidation of the Alkenes, Oxford University Press, New York, 2000, pp. 172-335.

4 R. M. Kamens and A. Jaoui, Modeling Aerosol Formation from $\alpha$-Pinene $+\mathrm{NO}_{x}$ in the Presence of Natural Sunlight Using Gas-Phase Kinetics and Gas-Particle Partitioning Theory, Environ. Sci. Technol., 2001, 35, 1394-1405.

5 L. Baptista, R. Pfeifer, E. C. da Silva and G. Arbilla, Kinetics and Thermodynamics of Limonene Ozonolysis, J. Phys. Chem. A, 2011, 115, 10911-10919.

6 S. Moukhtar, B. Bessagnet, L. Rouil and V. Simon, Monoterpene Emissions from Beech (Fagus sylvatica) in a French Forest and Impact on Secondary Pollutants Formation at Regional Scale, Atmos. Environ., 2005, 39, 3535-3547.

7 D. M. Pinto, P. Tiiva, P. Miettinen, J. Joutsensaari, H. Kokkola, A. Nerg, A. Laaksonen and J. K. Holopainen, The Effects of Increasing Atmospheric Ozone on Biogenic Monoterpene Profiles and the Formation of Secondary Aerosols, Atmos. Environ., 2007, 41, 4877-4887.

8 A. M. Jonsson, M. Hallquist and H. Saathoff, Volatility of Secondary Organic Aerosols from the Ozone Initiated
Oxidation of $\alpha$-Pinene and Limonene, J. Aerosol Sci., 2007, 38, 843-852.

9 J. Kesselmeier and M. J. Staudt, Biogenic Volatile Organic Compounds (VOC): An Overview on Emission, Physiology and Ecology, Atmos. Chem., 1999, 33, 23-88.

10 V. G. Khamaganov and R. A. Hites, Rate Constants for the Gas-Phase Reactions of Ozone with Isoprene, $\alpha$ - and $\beta$ Pinene, and Limonene as a Function of Temperature, $J$. Phys. Chem. A, 2001, 105, 815-822.

11 S. Leungsakul, M. Jaoui and R. M. Kamens, Kinetic Mechanism for Predicting Secondary Organic Aerosol Formation From the Reaction of $d$-Limonene with Ozone, Environ. Sci. Technol., 2005, 39, 9583-9594.

12 V. M. Ramírez-Ramírez and I. Nebot-Gil, Theoretical Study of the $\mathrm{OH}$ Addition to the Endocyclic and Exocyclic Double Bonds of the $d$-Limonene, Chem. Phys. Lett., 2005, 409, 2328.

13 Y. Shu and R. Atkinson, Rate Constants for the Gas-phase Reactions of $\mathrm{O}_{3}$ with a Series of Terpenes and $\mathrm{OH}$ radical Formation From the $\mathrm{O}_{3}$ reactions with Sesquiterpenes at $296 \pm 2$ K, Int. J. Chem. Kinet., 1994, 26, 1193-1205.

14 J. Zhang, K. E. H. Hartz, S. N. Pandis and N. M. Donahue, Secondary Organic Aerosol Formation from Limonene Ozonolysis: Homogeneous and Heterogeneous Influences as a Function of $\mathrm{NO}_{x}, J$. Phys. Chem. A, 2006, 110, 1105311063.

15 L. Jiang, W. Wang and Y. Xu, $A b$ initio Investigation of $\mathrm{O}_{3}$ addition to Double Bonds of Limonene, Chem. Phys., 2010, 368, 108-112.

16 S. Ayadi and M. Abderrabba, Density Functional Theory (DFT) Study of the Addition Reactions of Ozone on the Double Bonds of the Terpenes: Limonene, $\beta$-Phellandrene, and Terpinolene, Can. J. Chem., 2011, 89, 703-708.

17 S. Cradock and A. J. Hinchcliffe, Matrix Isolation. Cambridge University Press, Cambridge, 1975.

18 L. Andrews and M. Moskovits, Chemistry and Physics of Matrix-Isolated Species, Elsevier Science Publishers, Amsterdam, 1989.

19 C. K. Kohlmiller and L. Andrews, Infrared spectrum of the primary ozonide of ethylene in solid xenon, J. Am. Chem. Soc., 1981, 103, 2578-2583.

20 L. Andrews and C. K. Kohlmiller, Infrared spectra and photochemistry of the primary and secondary ozonides of propene, trans-2-butene, and methylpropene in solid argon, J. Phys. Chem., 1982, 86, 548-4557.

21 M. D. Hoops and B. S. Ault, Matrix isolation study of the early intermediates in the ozonolysis of cyclopentene and cyclopentadiene: observation of two Criegee intermediates, J. Am. Chem. Soc., 2009, 131, 2853-2863.

22 M. Clay and B. S. Ault, Infrared matrix isolation and theoretical study of the initial intermediates in the reaction of ozone with cis-2-butene, J. Phys. Chem. A, 2010, 114, 2799-2805.

23 J. G. Deng, J. H. Chen, C. M. Geng, H. J. Liu, W. Wang, Z. P. Bai and Y. S. Xu, The overall reaction process of ozone with methacrolein and isoprene in the condensed phase, J. Phys. Chem. A, 2012, 116, 1710-1716. 
24 C. Lv, L. Du, S. Tang, N. T. Tsona, S. Liu, H. Zhao and W. Wang, Matrix isolation study of the early intermediates in the ozonolysis of selected vinyl ethers, $R S C A d v$., 2017, 7, 19162-19168.

25 P. Wang, N. Zhao and Y. Tang, Halogen Bonding in the Complexes of $\mathrm{CH}_{3} \mathrm{I}$ and $\mathrm{CCl}_{4}$ with Oxygen-Containing Halogen-Bond Acceptors, J. Phys. Chem. A, 2017, 121, 50455055.

26 M. J. G. Frisch, G. W. Trucks, H. B. Schlegel, G. E. Scuseria, M. A. Robb, and J. R. Cheeseman, et al., Gaussian 09, revision A. 02, Gaussian Inc., Wallingford, CT, 2009.

27 Y. Zhao and D. G. Truhlar, The M06 suite of density functionals for main group thermochemistry, thermochemical kinetics, noncovalent interactions, excited states, and transition elements: two new functionals and systematic testing of four M06-class functionals and 12 other functionals, Theor. Chem. Acc., 2008, 119, 525.
28 I. M. Alecu, J. Zheng, Y. Zhao and D. G. Truhlar, Computational Thermochemistry: Scale Factor Databases and Scale Factors for Vibrational Frequencies Obtained from Electronic Model Chemistries, J. Chem. Theory Comput., 2010, 6, 2872-2887.

29 S. Canneaux, F. Bohr and E. Henon, KiSThelP: a program to predict thermodynamic properties and rate constants from quantum chemistry results, J. Comput. Chem., 2014, 35, 8293.

30 S. Wierlacher, W. Sander, C. Marquardt, E. Kraka and D. Cremer, Propinal O-oxide, Chem. Phys. Lett., 1994, 222, 319-324.

31 W. Subhan, P. Rempala and R. S. Sheridan, pPhenylenebismethylene: characterization, calculation, and conversion to a conjugated bis-carbonyloxide, J. Am. Chem. Soc., 1998, 120, 11528-11529. 